MATEC Web of Conferences 22,04024 (2015)

DOI: $10.1051 /$ matecconf/ 20152204024

(C) Owned by the authors, published by EDP Sciences, 2015

\title{
A Study of PHC Pipe Pile Vertical Ultimate Bearing Capacity Calcula- tion Method and its Numerical Simulation Analysis
}

\author{
Xin Zhou \& Guangxiu Fang * \\ Department of Building Structural Engineering, Yanbian University, Yanji, Jilin, China
}

\begin{abstract}
According to the PHC pipe pile design of Xinwan Plaza, Huaiyuan, Anhui and pile test results of static sounding method and experience method using the ultimate bearing capacity of single pile are calculated, considering the effect of soil plug the influence of vertical ultimate bearing capacity of single pile, and the formula for calculating the lateral resistance and end resistance, static sounding method and the correction formula to calculate the bearing capacity calculated results was coincident with the results of test pile. Combining with the project of Xinwan Plaza, Huaiyuan, Anhui, through the static load test, a study of the load transfer mechanism of PHC pipe pile, analyzes the vertical load, the change rule of the settlement of pile body and pile and the use of finite difference software FLAC3D simulation of the PHC pipe pile static load test, the simulation results agreed with the measured load-settlement curve.
\end{abstract}

Keywords: PHC pipe pile; Static sounding method; Single pile vertical ultimate bearing capacity; Correction; Experience parameter method; FLAC3D software; The numerical simulation

\section{INTRODUCTION}

PHC pipe pile, which has been widely used in industrial and civil buildings, railways, highways, bridges and other projects is a kind of high strength prestressed concrete pipe pile, and it has high bearing capacity, stable quality, low price and fast construction speed. By the construction of prestressed pipe pile bearing capacity and pile soil interaction, the influence of such factors as the current engineering for its load-bearing mechanism is still in the stage of exploration. The analysis of the prestressed concrete pipe pile design is mainly through the model test and in-situ test. Due to the load transfer mechanism of tubular pile, the bearing performance of various influential factors such as lack of systems analysis and comparison, the process of load transfer of piles, the reasonable design, construction and test of pile foundation have great significance.

\section{PROJECT SUMMARY AND GEOLOGICAL CONDITIONS}

Xinwan plaza project is located in the east of Xinhe Road, Huaiyuan, Anhui, which has three buildings Building A, B, and C. Garage and equipment rooms are on the underground layer. A building for A class is a high-rise building, whose height is $99.6 \mathrm{~m}$, with 29 floors as total. Building B and C are residential buildings with eighteen floors, both of whose height are $58.9 \mathrm{~m}$. The total construction area of the three buildings is $57,500 \mathrm{~m}^{2}$. Natural geographic unit belongs to

*Corresponding author: gxfang@ybu.edu.cn the flood land of Huaihe River, and the topography around is relatively flat with the relative elevation between $18.00 \mathrm{~m}$ and $20.08 \mathrm{~m}$

From exploration and revealing the formation of data analysis, site $50 \mathrm{~m}$ depth within the scope of the foundation soil is mainly consisted of the glue powder in the soil, sandy silt and fine sand. According to its sedimentary s, the differences between the genetic types and its physical and mechanical properties can be divided into four engineering geology layer. (1) Filling soil has such geotechnical characteristics as: noise, loose, and wet, containing a small amount of construction waste, giving priority to the clay, and the layer strength is poor, and groove excavation should be clear; (2) the powder soil has such geotechnical characteristics as: further to grey, loose, wet, shock response of medium, low dry strength, toughness is low lacklustre, low local bearing capacity of silty clay, and the layer thickness is larger, and the stable horizon and compressibility are not perfect as the pile foundation bearing layer; (3) sandy silt has such geotechnical characteristics as: gray, a bit tight, wet, shake vibration reaction medium, better sorting characteristics, and the main mineral is given priority to with quartz, mica, feldspar, sandwiched thin layer of silty clay and containing a small amount of shell fragments, containing silty sand, the bearing capacity of the layer, large thickness, layer stability, appropriate as the pile foundation bearing layer; (4) medium sand has such geotechnical characteristics as: further to grey, to close-grained, wet, seismic response of medium, low dry strength, toughness is low, and the main mineral is given priority to with quartz, mica, feldspar, partial thin silty clay layer, containing silty sand, the layer of high bearing capacity, stable horizon, big thickness, 


\section{MATEC Web of Conferences}

appropriate for pile foundation bearing layer and the lower layer.

This project design uses wall thickness $(100 \mathrm{~mm})$ of PHC pipe piles, pile length is $25 \mathrm{~m}$, diameter of 500 $\mathrm{mm}$, for C80 concrete strength, and the effective pile length is about $25 \mathrm{~m}$.

\section{STATIC LOAD TEST AND ANALYSIS}

Three root pile static load tests are respectively for $8 \#$, $148 \#$, and $257 \#$. The maximum load tests of these three root piles are conducted according to the $3600 \mathrm{kN}$.

\subsection{Test load}

According to building pile foundation technology standard and construction pile foundation inspection specification, single pile static load test, the extrapolation load, load method maintains at the slow tempo. Load and stabilize the QF630-20 type hydraulic jack and an electric oil pump, using two radial displacement sensors in a wide range of weighing measuring on the top of the pile settlement, displacement observation record the JCQ - 302 type static load tester, load arrangement as shown in Figure 1. The sum capacity is $3600 \mathrm{kN}$, which is divided into 9 loads, and every load increment is $400 \mathrm{kN}$. The experiment goes well, under maximum load test pile settlement of pile top which is less than $40 \mathrm{~mm}$, with no obvious increase subsidence phenomenon, and the test piles have not reached the ultimate bearing state.

\subsection{Test results and analysis}

The results of pile static load test are shown in Table 1. The Q-S curve of 8\#, 148\#, 257\# root pile is shown in Figure 1.

Table 1. Static load test results

\begin{tabular}{lll}
\hline $\begin{array}{l}\text { Pile } \\
\text { NO. }\end{array}$ & $\begin{array}{l}\text { The maximum test } \\
\text { load/kN }\end{array}$ & $\begin{array}{l}\text { The maximum test load } \\
\text { of pile top settle- } \\
\text { ment/mm }\end{array}$ \\
\hline 8 & 3600 & 13.44 \\
148 & 3600 & 11.56 \\
257 & 3600 & 19.23 \\
\hline
\end{tabular}

Seen from Figure 1, when the maximum load test is $3600 \mathrm{kN}$, which indicates that the test pile settlement is stable at all levels of loads, the Q - S curve lines are similar with slow deformation and no obvious bending steep fall, and the settlement was less than $40 \mathrm{~mm}$, namely 3 root pile tests did not reach the limit state, and the ultimate bearing capacity can be thought not less than $3600 \mathrm{kN}$, which is adopted in this paper, in order to better forecast the load settlement value of origin software load-settlement for polynomial fitting, and the fitting result is shown in Figure 2. Fitting curve equation is $\mathrm{y}=\mathrm{ax}^{2}+\mathrm{bx}+\mathrm{c}$, where, $\mathrm{a}=6.51177$ $\mathrm{e}-6, \mathrm{~b}=0.00145$, and $\mathrm{c}=0.20905$, and the results show that $R^{2}=0.9987$, and the fitting is good.

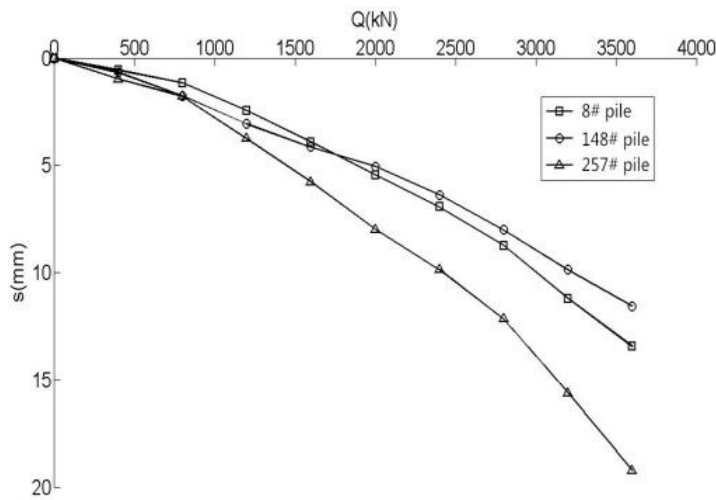

Figure 1. Static load test load-settlement curve

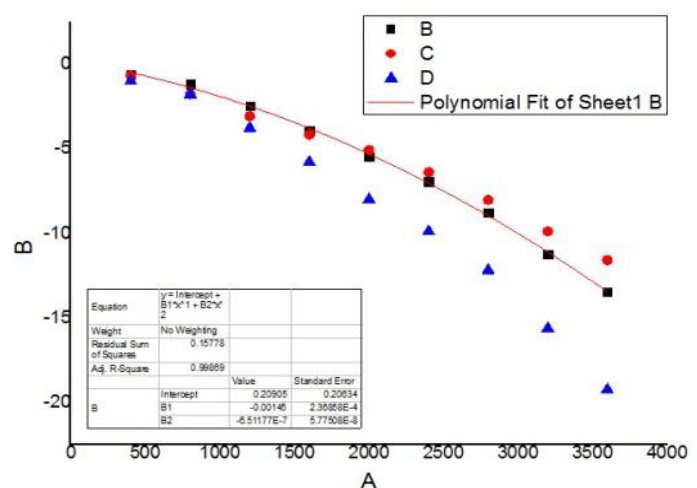

Figure 2. Static load test load-settlement curve.

\section{BEARING CAPACITY CALCULATION}

\subsection{Static sounding method}

In the specification given in the article 5.3.4, on cohesive soil, powder soil and sandy soil, static sounding data build probes are used to determine single pile vertical ultimate bearing capacity of precast concrete pile standard calculation formula:

$$
Q_{u k}=Q_{s k}+Q_{p k}=u \sum l_{i} \cdot \beta_{i} \cdot f_{s i}+\alpha \cdot q_{c} \cdot A_{p}
$$

Where: Quk stands for single pile vertical ultimate bearing capacity standard $(\mathrm{kN})$, Qsk stands for total ultimate lateral resistance values $(\mathrm{kN})$, Qpk stands for total ultimate end resistance standard $(\mathrm{kN}), \mathrm{u}(\mathrm{m})$ 
ICETA 2015

Table 2. Conical resistance, wall resistance and other values of the J11 J13 J18 and J25drill hole

\begin{tabular}{llllll}
\hline Hole no. & The soil & Thickness $(\mathrm{m})$ & $\begin{array}{l}\text { Cone tip } \\
\mathrm{qc} / \mathrm{mPa}\end{array}$ & $\begin{array}{l}\text { resistance } \\
\text { Jide resistance } \\
\mathrm{fs} / \mathrm{kPa}\end{array}$ & $\begin{array}{l}\text { Friction than } \\
\mathrm{Rf} / \%\end{array}$ \\
\hline \multirow{3}{*}{$\mathrm{N}$} & $(1)$ & 0.60 & 1.86 & 18.3 & 1.0 \\
& $(2)$ & 11.80 & 7.11 & 50.8 & 0.7 \\
& $(3)$ & 7.10 & 15.20 & 90.9 & 0.6 \\
$\mathrm{~J} 13$ & $(4)$ & 16.80 & 16.35 & 81.1 & 0.5 \\
& $(1)$ & 0.70 & 1.66 & 6.1 & 0.4 \\
& $(2)$ & 10.40 & 15.25 & 54.5 & 0.4 \\
& $(3)$ & 6.50 & 29.46 & 101.5 & 0.3 \\
$\mathrm{~J} 18$ & $(4)$ & 19.00 & 21.42 & 151.7 & 0.6 \\
& $(1)$ & 0.80 & 1.68 & 10.1 & 0.6 \\
& $(2)$ & 11.40 & 15.49 & 56.5 & 0.4 \\
& $(3)$ & 6.30 & 30.06 & 106.7 & 0.4 \\
$\mathrm{~J} 25$ & $(4)$ & 16.90 & 21.15 & 138.5 & 0.7 \\
& $(1)$ & 0.60 & 0.78 & 1.3 & 0.6 \\
& $(2)$ & 11.10 & 17.54 & 63.4 & 0.4 \\
& $(3)$ & 7.80 & 30.94 & 96.8 & 0.4 \\
& $(4)$ & 17.30 & 18.48 & 103.9 & 0.7 \\
\hline
\end{tabular}

Table 3. The design parameters of pile foundation

\begin{tabular}{lllcl}
\hline Stratigraphic no. & Stratigraphic name & $\begin{array}{l}\text { Extreme lateral resistance } \\
\text { standard }\end{array}$ & $\begin{array}{c}\text { Ultimate end resistance standard } \\
\mathrm{q}_{\mathrm{pk}}(\mathrm{kPa})\end{array}$ \\
\hline$(2)$ & & $\mathrm{q}_{\text {sik }}(\mathrm{kPa})$ & \\
$(3)$ & silt & 25 & & 1900 \\
$(4)$ & Sandy silt & 50 & 5500 & \\
\hline
\end{tabular}

stands for the pile body circumference, Li stands for the ith soil layer thickness $(\mathrm{m})$, and $\beta_{\mathrm{i}}$ is the ith layer soil pile side resistance comprehensive correction coefficient, , fsi is the ith layer soil probe lateral resistance $(\mathrm{kPa})$ on average, $\alpha$ stands for the correction coefficient of pile side resistance for taking $2 / 3$ of cohesive soil, with powder soil, saturated sand taken $1 / 2$. qc stands for pile platforms, under the surface, the probe resistance, taking the pile end plane above $4 \mathrm{~d}(\mathrm{~d}$ is the diameter of the pile or side) according to soil layer thickness sensor resistance within the scope of a weighted average $(\mathrm{kPa})$, and then the pile end plane within the scope of the $1 \mathrm{~d}$ probes the average resistance value $(\mathrm{kPa}) ; A_{\mathrm{p}}$ stands for the pile end area $\left(\mathrm{m}^{2}\right)$. The formula for computing application conditions is as follows: to build the probe cone bottom area of $15 \mathrm{~cm}^{2}$, taper angle $60^{\circ}$, friction sleeve $21.85 \mathrm{~cm}$ high, and side area is $300 \mathrm{~cm}$. My unit for static sounding car with $20 \mathrm{t}$ builds probe data meeting above requirements.

Internal forces by field static sounding data compilation for four static probe hole data $(\mathrm{J} 11, \mathrm{~J} 13, \mathrm{~J} 18$, $\mathrm{J} 25$ ), as well as stipulated in the specification of each soil layer thickness calculation of each soil layer side resistance and cone tip resistance are shown in Table 2.

Formula (1) of the pile body circumference $\mathrm{u}=1.57$ $\mathrm{m}$. (2), (3) layer soil pile side resistance comprehensive correction coefficient $\beta_{i}=10.04\left(\mathrm{f}_{\mathrm{si}}\right)^{-0.55}$, (4) layer $\beta_{i}=5.05\left(\mathrm{f}_{\mathrm{si}}\right)^{-0.45}$; take $1 / 2$ pile side resistance correction coefficient, and pile tip into the depth of the bearing layer is greater than $4 \mathrm{~d}$, so $\mathrm{q}_{\mathrm{c}}$ resistance on pile carry even under the surface, the probe is 16.35 $\mathrm{kPa}$.

Calculated as stipulated in the specification of J11, pile side always limits standard lateral resistance and end resistance of standard values is:

$$
Q_{u k}=Q_{s k}+Q_{p k}=345695 \mathrm{kN}
$$

By the same token, the calculation of J13 as stipulated in the specification, J18, J25 number pile ultimate bearing capacity standard values. Calculation results are shown in Table 4.

To calculate the field calculation of pile side resistance limit as stipulated in the specification mean value of $2719.64 \mathrm{kN}$, average resistance on pile side limit end is $1215.18 \mathrm{kN}$, and single pile vertical compressive ultimate bearing capacity of the mean value is $3934.82 \mathrm{kN}$

\subsection{Experience parameter method}

Article in the "specification" 5.3.8, when according to the physical index and the bearing capacity of soil parameters determine the empirical relationships between exposure to single pile vertical ultimate bearing capacity of prestressed concrete hollow pile standards, which can be calculated by the following formula:

$$
Q_{u k}=Q_{s k}+Q_{p k}=u \sum q_{s i k} l_{i}+q_{p k}\left(A_{j}+\lambda_{p} A_{p 1}\right)
$$




\section{MATEC Web of Conferences}

$\begin{gathered}\text { When } \\ \lambda_{p}=0.8\end{gathered} \quad h_{b} / d<5, \quad \lambda_{p}=0.16 h_{b} / d \quad$, when $\quad h_{b} / d \geq 5$,

$A_{j}$ is the hollow pile end net area; ${ }_{j}=\frac{\pi}{4}\left(d^{2}-d_{1}^{2}\right)$; ${ }_{A}{ }_{p 1}$ is the hollow pile exposure area; ${ }^{A} p 1=\frac{\pi}{4} d_{1}^{2} ; \lambda_{p}$ stands for the pile endpoint soil plug effect coefficient; $h_{b}$ stands for Pile tip into the bearing layer depth;d and $\mathrm{b}$ stands for the hollow pile diameter and length; $d_{1}$ stands for the hollow pile diameter.

According to static sounding data from the field, the PHC pipe pile length is $25 \mathrm{~m}$. Check the specifications available to the limit of the layers of soil pile side friction standard qsik and (4) layer of fine sand ultimate end resistance standardqpk, whichi is shown in Table 3.

According to the experience of the "standard" method calculation formula is as follows:

$Q_{s k}=u \sum q_{s i k} l_{i}=1.57(25 \times 11.80+50 \times 7.10+5.5 \times 75)=166813 \mathrm{kN}$

J13, J18, J25 number aperture limit frictional resistance values are $1789.81 \mathrm{kN}, 1707.38 \mathrm{kN}, 1695.61$ $\mathrm{kN}$.

Four static aperture limit end resistance values are:

$Q_{p k}=q_{p k}\left(A_{j}+\lambda_{p}{ }_{p 1}\right)=5500<(0.1256+0.8 \times 0.07065)=107938 \mathrm{kN}$

Stipulated in accordance with the specification of the experience method to calculate the average resistance on pile side limit side, this site is $1715.23 \mathrm{kN}$, pile end limit end resistance is $1079.38 \mathrm{kN}$, and vertical compressive ultimate bearing capacity of single pile standard value is $2794.61 \mathrm{kN}$.

Literature [2] on the premise of considering the lining of pile side friction correction formula is established, and the correction formula is as follows:

$Q_{u k}=Q_{s k}+Q_{p k}=\left(u_{1}+a u_{2}\right) \sum q_{s i k} l_{i}+b q_{p k} A_{p}$

Where: $\mathrm{u}_{1}, \mathrm{u}_{2}$ are the circumferences of the outer wall and inner wall; for soil plug effect correction coefficient, viscous soil powder soil and sandy soil are $0.3,0.5$ and 0.6 respectively; $b$ stands for the ultimate end correction coefficient of resistance standard value of 1.2; other parameters are the same with formula (2).

Calculated according to the formula (3): J11 J13, $\mathrm{J} 18$, J25 hole number limit friction resistance values are: $2468.83 \mathrm{kN}, 2648.92 \mathrm{kN}, 2526.92 \mathrm{kN}, 2509.50 \mathrm{kN}$. Four static aperture limit of end resistance values are: $1295.26 \mathrm{kN}$.

Then the vertical compressive ultimate bearing capacity of single pile standard value is $2317.02 \mathrm{kN}$. And static load test result of single pile vertical ultimate bearing capacity standard is $2800 \mathrm{kN}$, which is about $17.25 \%$ lower than the measured values.

\subsection{Comparison and analysis}

Comparison and analysis results are shown in Table 4.

Table 4. Comparison and analysis results

\begin{tabular}{|c|c|c|c|c|c|c|c|c|c|c|}
\hline \multirow[b]{2}{*}{$\begin{array}{l}\text { Calculation } \\
\text { mitiond }\end{array}$} & \multicolumn{3}{|c|}{ Formida (1) } & \multicolumn{3}{|c|}{ Formula (2) } & \multicolumn{3}{|c|}{ Formula (3) } & \multirow{2}{*}{ 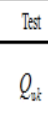 } \\
\hline & $Q_{\dot{k}}$ & $Q_{p k}$ & $Q_{k k}$ & $Q_{\dot{k}}$ & $Q_{p k}$ & $Q_{v k}$ & $Q_{i}$ & $Q_{p k}$ & $Q_{v k}$ & \\
\hline $\mathrm{J} 11$ & 2430.17 & 1026.78 & 3456.95 & 1668.13 & 1079.38 & 2477.51 & 2468.83 & 1205.26 & 3764.09 & \\
\hline $\mathrm{J} 13$ & 2739.14 & 1345.18 & 4084.32 & 1789.81 & 1079.38 & 2869.19 & 2648.92 & 129526 & 394.18 & \\
\hline $\mathrm{J} 18$ & 2692.23 & 1328.22 & 4020.45 & 1707.38 & 1079.38 & 2786.76 & 25260.92 & 1205.26 & 382218 & 23600 \\
\hline$\sqrt{225}$ & 2655.22 & 1160.54 & 3815.76 & 1609.61 & 1079.38 & 2774.99 & 2509.50 & 1295.26 & 3804.76 & \\
\hline The arragee & 2629.19 & 1215.18 & 384.37 & 17715.23 & 1079.38 & 2794.61 & 2538.54 & 1295.26 & 3833.80 & \\
\hline The ratio & 0.730 & 0.337 & $\leq 1.068$ & 0.477 & 0.299 & $\leq 0.776$ & 0.705 & 0.360 & $\leq 1.065$ & \\
\hline
\end{tabular}

We can see from the result of comparison: (1) the static sounding method to calculate the result is not greater than $6.8 \%$ but higher than experimental results, the revised formula calculation results is not more than $6.5 \%$ but higher than experimental results, and the empirical formula method to calculate the results below the test value is not less than $22.4 \%$; from the point of load-settlement curve, the trend of the settlement of the pile deformation is relatively flat, no damage characteristics of the steep falling in, and still has considerable potential. Static sounding method to show the calculation results and the revised formula is applicable in this project, after accumulating experience, along the Huai region it can be applied in Bengbu, and empirical formula law requires its bearing capacity of pile tip and pile lateral coefficient is revised to use; (2) in both static sounding method from experience parameter method, limit the lateral resistance of the percentage of the ultimate bearing capacity is greater than the resistance ratio of the ultimate end, which shows that the engineering PHC pipe piles for friction piles mechanically are mainly composed of pile side resistance.

\section{FLAC3D SIMULATION ANALYSIS}

\subsection{Establishment of calculation model}

(1) boundary conditions and soil parameters Model analysis of the area: the pile lateral soil calculation to 10 times the pile diameter, pile end computing to pile end plane outside the following 15 times the pile diameter. Free at the top of the pile, the pile end 15 times the pile diameter outside the scope of the plane is fixed, and the four sides of pile lateral soil are only in the vertical displacement, and along the direction of the pile length is what is fixed and the other two directions. The soil and pile basic parameters of Xinwan Plaza project are shown in Table 2.

(2) The geometric model 


\section{ICETA 2015}

The numerical simulation of model reference to engineering static load test of pile length is $25 \mathrm{~m}$ of PHC pipe piles, pile diameter is $500 \mathrm{~mm}$ and wall thickness is $100 \mathrm{~mm}$ (with static load test of pile type). For each soil (along the $\mathrm{z}$ axis is down): $0 \sim 1.0$ miscellaneous fill, $1.0 \mathrm{~m}$ to $1.0 \mathrm{~m}$ sandy silt, $11.0 \mathrm{~m}$ to $11.0 \mathrm{~m}$ silt, $18.0 \mathrm{~m}$ to $36.0 \mathrm{~m}$ medium sand. Take $1 / 2$ of the model to calculate. Geometric model is shown in Figure 3.

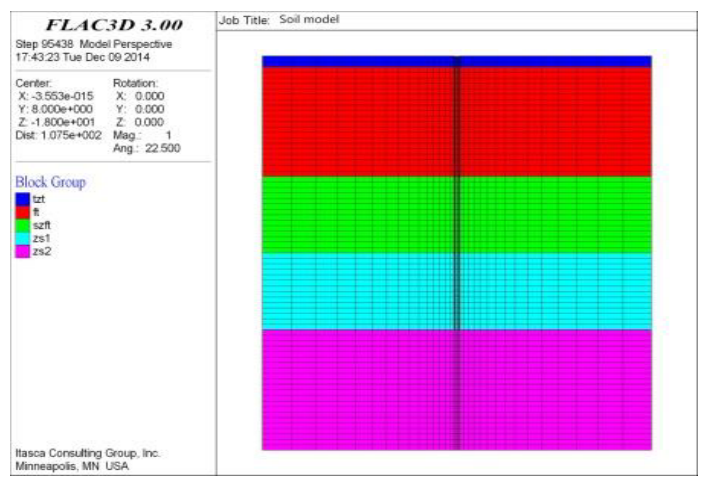

(a)

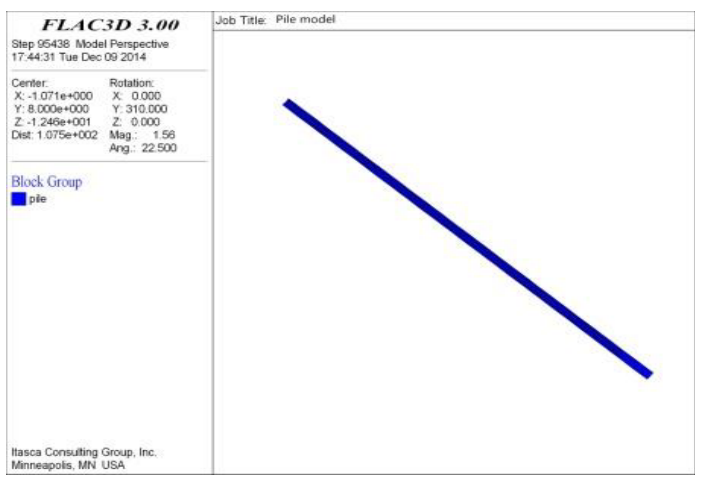

(b)

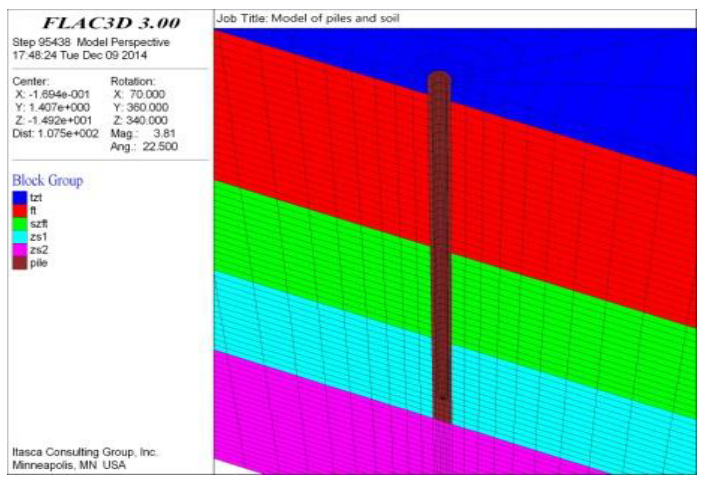

(c)

Figure 3. The geometric model of pile and soil

Under the action of gravity, pile and soil of the initial stress field and unbalanced convergence process are shown in Figure 4: the figure shows the model of gravity stress distribution of fundamental equilibrium, the largest imbalance force good convergence.

\subsection{The numerical simulation analysis}

Because this model mainly considers force and settlement of pile top, the pile-soil model begins to become hierarchical load pile after reaching balance under the gravity. Head points are distributed vertically, nine times loading step by step, and the initial load is $400 \mathrm{kN}$, since load increases $400 \mathrm{kN}$ by each level, every change after loading the output displacement of pile head, and the whole simulation process is a force displacement to solve the problem.

The PHC pipe pile of Xinwan Plaza project is carried on with pile length of $25 \mathrm{~m}$ and $\mathrm{PHC}$ pile type of AB500 (100), and the load of $3600 \mathrm{kN}$ of stress nephogram is shown in Figure 5:
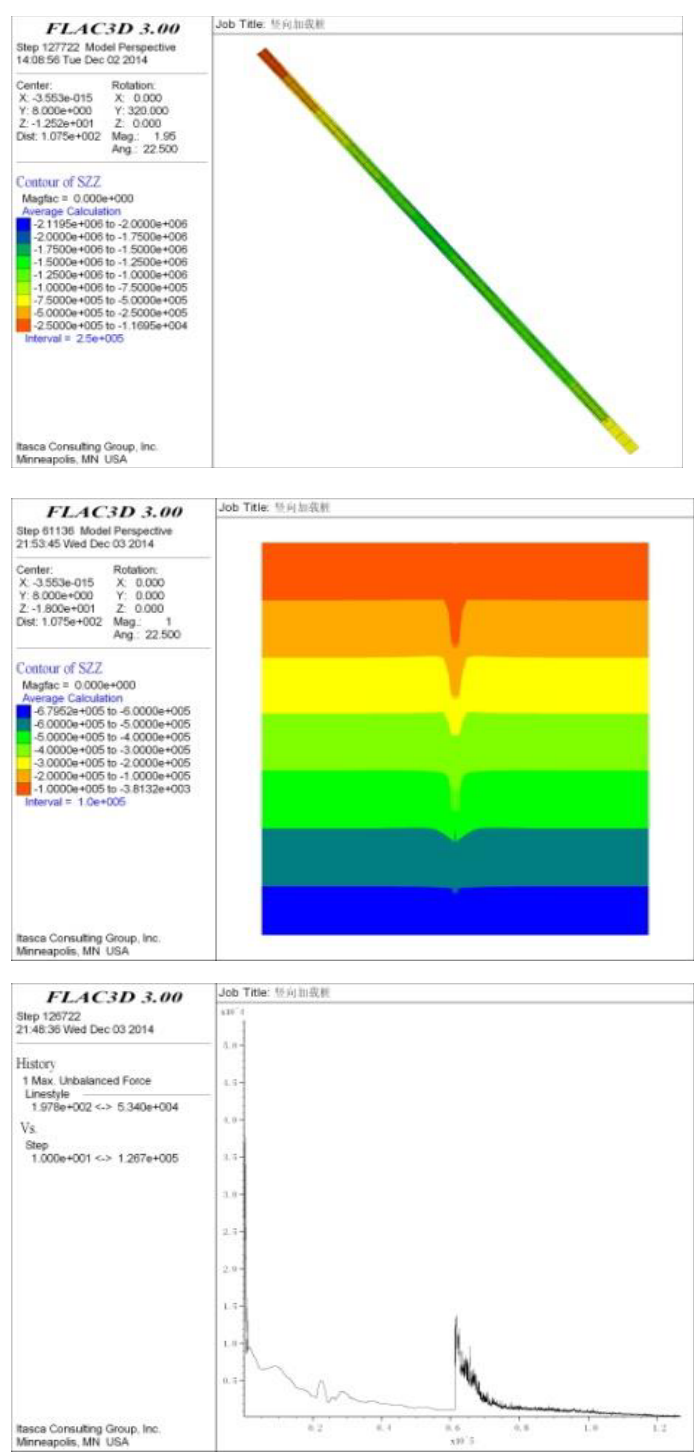

Figure 4. The initial pile and soil stress convergence process of stress field and unbalanced 


\section{MATEC Web of Conferences}

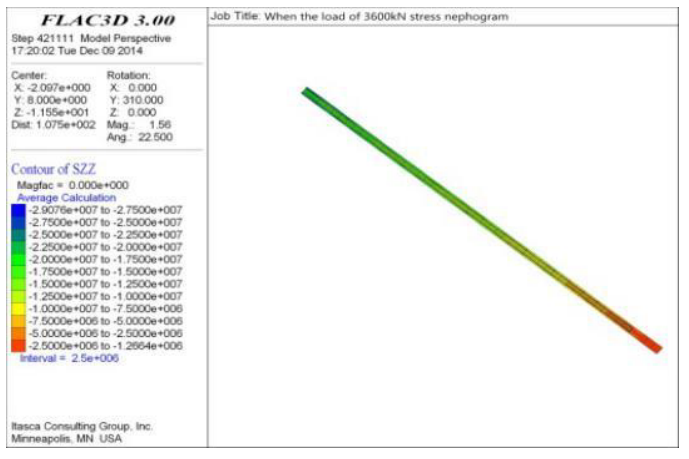

Figure 5. The curves of axial force on the depth of pile body

After each load output displacement value of pile top, tidy load-settlement curve is shown in Figure 6:

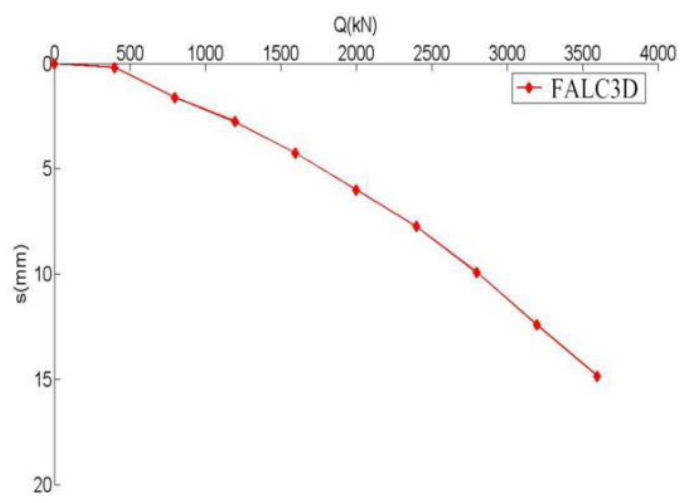

Figure 6. Numerical simulation of the pipe pile Q $\sim \mathrm{S}$ curve

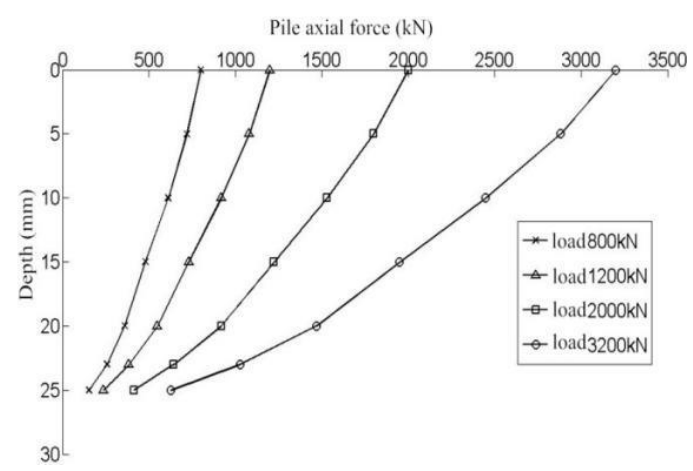

Figure 7. The curves of axial force on the depth of pile body

According to FALC3D simulation of pile body stress nephogram, render the PHC pipe pile axial force of the project along with the change of load curve. Figure 8 shows the curve of pile axial force and the pile depth change when the load is $800 \mathrm{kN}, 1200 \mathrm{kN}$,
$2000 \mathrm{kN}$ and $2000 \mathrm{kN}$. The figure can show that in the axial force of pile and pile deep relationship between the approximate linear relationships, pile jacking force is approximate to piling force. As a result of the existence of pile side friction and axial force along the pile shaft and decreases, it will not reduce to zero in the end, because the pile end can also share the resistance. With the increase of load, pile end resistance is also on the increase, and it just shows a slight change. As can be seen from the diagram, pile end resistance only accounts for a small part of it. Like the friction pile, the PHC pipe pile stress is mainly composed of pile side resistance.

\subsection{Contrastive analysis of the static load test and numerical simulation data}

To sum up, according to the test data of 8 \#, 148 \# and 257 \# pile static load test, as is shown in Figure 2 and Figure 3, the load-settlement curve contrast figure are shown in Figure 9 below. Figure 10 is to simulate the settlement of pile body figure when the load is $4000 \mathrm{kN}$.

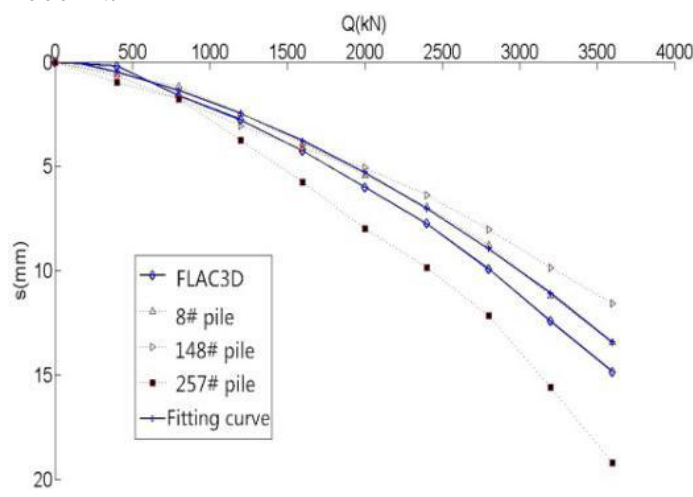

Figure 8. The Q $\sim \mathrm{S}$ curve comparison chart

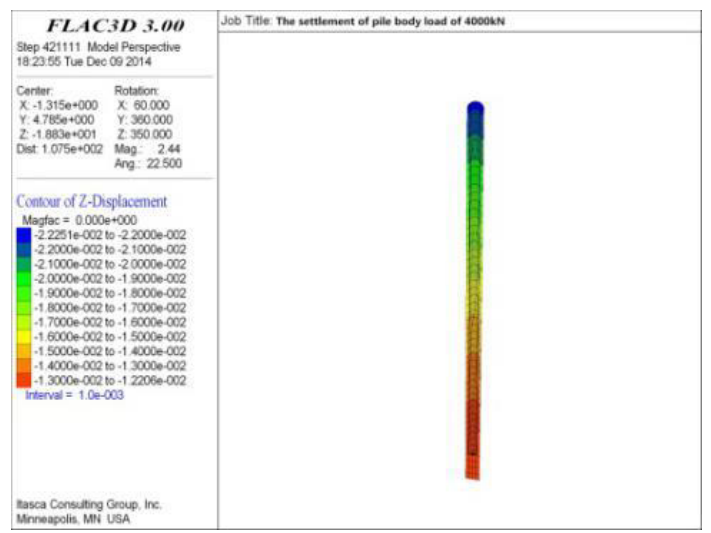

Figure 9. When the loading of the pile settlement is $4000 \mathrm{kN}$

Figure 8 shows the simulation results and the measured load coincided basically with the settlement 
curve, but there are certain differences, partly because simulations due to compaction effect, the soil parameters are difficult to be precise, on the other hand, due to the simulation of not considering the pore water pressure dissipation process and interface features. Specify that the parameters and using FLAC3D software simulation calculation results of PHC pipe pile is reliable. As can be seen in Figure 9, when the load is $4000 \mathrm{kN}$, pile settlement is $26 \mathrm{~mm}$, it's still less than $40 \mathrm{~mm}$, proving that the bearing capacity of pipe pile is still fairly potential.

\section{CONCLUSION}

This article calculates the vertical ultimate bearing capacity of PHC pipe pile in Xinwan Plaza project through static sounding method. Comparisons and analyses are summarized as follows:

(1) From the calculation process, the static sounding data to estimate the PHC pipe pile with vertical ultimate bearing capacity of the standard, the method is simple, and the calculation process is not complicated with static test data for original data, but the pile end qc value calculation is more complicated. For experience parameters method, the data is estimated with no direct static test data. Static test data at the same time also can adopt a hole, and the above points than experience parameter method is superior.

(2) From the calculation results, the empirical parameter method for calculating the static sounding data calculation of numerical value is less than the revised formula of experience method static sounding method and the calculation results are close. For this project, if static sounding method or the revised by experience formula to calculate the parameter method of numerical value is given priority, as a preliminary design of pile foundation parameters, it can effectively reduce the waste of manpower and material resources on the project.

(3) From the adaptability, Bengbu geomorphic unit types for the Huaihe River flood plain along the Huai region, mainly investigated for viscous soil, powder soil and sandy soil. Static sounding is suitable for the geological environment, and can also better reflect the pile.

(4) From the accuracy, the static sounding method and the experience of the revised parameter method to calculate the result is closer to the pile test results. But to verify its accuracy it still needs more information.

In this paper, FLAC3D simulation of the load-bearing characteristics of PHC pipe pile, based on the analysis of previous research results and master the basis of the theory of FLAC, compiles the FLAC3D simulation command flow pipe pile load-bearing characteristics. Combined with Xinwan Plaza project, through the analysis and study, conclusions are as follows:

(1) By FLAC3D simulation of the single pile static load test result shows that the prestressed concrete pipe pile is in the engineering of friction pile, and the stress is mainly composed of pile side resistance.

(2) The FLAC3D simulation results of the single pile load-settlement curve fit in with the site, showing that prestressed concrete pipe pile with FLAC3D software simulation calculation results are reliable.

(3) From the point of load-settlement curve, the trend of the settlement of the pile deformation is relatively smooth and there was no damage characteristic of steep fall, and thus it still has considerable bearing potential. FLAC3D simulation results verify this conclusion, and standardize the design calculation of engineering pile bearing capacity which is low, failing to make full use of its conservative design.

\section{ACKNOWLEDGEMENT}

The corresponding author of this paper is Guangxiu Fang. This paper is supported by the civil engineering construction technology teaching resource database construction fund projects (project number: 802014010), Yanbian University.

\section{REFERENCES}

[1] The industry standard of the People's Republic of China (JGJ94-2008). Building Pile Foundation Technical Specification.

[2] Yanshuang LI. 2010. Tianjin port Nanjiang south port PHC pipe pile bearing capacity of single pile sure. Master thesis, Tianjin University.

[3] Adel M. Hanna. 2006. Drag force on single piles in clay subjected to surcharge loading. International Journal of Geomechanics ASCE. 80(7): 89-96

[4] Chunfeng ZHAO. 2003. Static sounding to estimate the bearing capacity of single pile limit method research. Journal of Geotechnical Engineering, (10 : 408-410

[5] Zhang Junren. 2011. Static sounding data using estimates several realizations of the single pile vertical ultimate bearing capacity standard. Journal of Jilin Geological, 30 (1): $139 \sim 142$.

[6] Guowen Qiao, Yunsheng Wang, landlord constant. Some of the right of excavation slope stability of the power station of FLAC-(3d) analysis. Journal of Engineering Geology, 12 (3): 280-284.

[7] Zhao Zhen. 2009. Applying FLAC-(3D) Analysis of Prestressed Concrete Pipe Pile Load-bearing Characteristics Research. Nanchang University. 